\title{
Omnivory by the small cosmopolitan hydromedusa Aglaura hemistoma
}

\author{
Sean P. Colin \\ Environmental Sciences, Roger Williams University, Bristol, Rhode Island 02918
}

John H. Costello

Biology Department, Providence College, Providence, Rhode Island 02908

\section{William M. Graham and John Higgins III}

Dauphin Island Sea Lab, 101 Bienville Boulevard, Dauphin Island, Alabama 36528

\begin{abstract}
We investigated the feeding of the small hydromedusa, Aglaura hemistoma (bell diameter $<4 \mathrm{~mm}$ ), to determine if it occupies a trophic position similar to that of large medusae. Feeding was examined using gut-content analysis of preserved and unpreserved medusae and by analyzing prey-capture events using microvideographic techniques. Analysis of gut contents and prey-capture events revealed that A. hemistoma fed heavily on protistan prey and that it possessed a prey-capture mechanism, specifically a feeding current, that is effective at entraining and capturing protists with low motility. We suggest that many species of small hydromedusae possess prey-capture mechanisms adapted to capture small protistan prey and that many of these small hydromedusae feed omnivorously on microplanktonic prey. The trophic roles of small hydromedusae in different systems are not understood and more studies are needed. However, based on their often high abundances and the cosmopolitan nature, if small hydromedusae are primarily omnivores, they need to be considered when estimating the impact of zooplankton on primary production and, more generally, protistan community dynamics.
\end{abstract}

Large medusae are widely recognized as important predators of crustacean zooplankton, fish eggs, and fish larvae and for their ability to structure marine coastal ecosystems through predation (Costello and Colin 1994; Behrends and Schneider 1995). The perceived ecological roles of medusae are based on the study of large species, primarily scyphomedusae, due to their conspicuous size and obvious trophic importance. Consequently, the trophic impact of the more numerous small medusan species has been assumed to be similar to that of large medusae or overlooked completely.

Diversity patterns suggest that the trophic role of small medusae should not be ignored. Small medusae, particularly small hydromedusae, are the most diverse group of gelatinous zooplankton in the world's oceans (Fig. 1). Hydromedusae contain more than twice as many species as any other major gelatinous zooplankton group and the majority of organisms are $<5 \mathrm{~mm}$ in diameter. They are numerically abundant and cosmopolitan and their population maxima often co-occur seasonally with peaks in phytoplankton biomass (e.g., Matsakis and Conover 1991; Costello and Mathieu 1995). However, with few exceptions (Purcell and Mills 1988), little is known about the trophic roles of small medusae despite their ubiquitous presence throughout marine pelagic ecosystems.

\footnotetext{
Acknowledgements

We are grateful for the support of the National Science Foundation (OCE-0116236 and OCE-0350834 awarded to J.H.C. and OCE0351398 awarded to S.P.C.), the Ministry of Science and Technology of the Republic of Croatia, and the Polytechnic of Dubrovnik (Croatia). We thank H. G. Dam, D. Gifford, B. K. Sullivan, and the anonymous reviewers for valuable comments that improved earlier drafts of the manuscript.
}

Our goal was to examine the feeding of Aglaura hemistoma, a small (bell diameter $<4.0 \mathrm{~mm}$ ) cosmopolitan hydromedusa that is common in temperate surface waters throughout the Atlantic and Indo-Pacific Oceans (Bouillon 1999). Specifically, we wanted to determine whether its trophic niche is similar to that of larger medusae. Our approach was to examine medusa gut contents in conjunction with an evaluation of prey-capture mechanisms to determine the trophic role of $A$. hemistoma. The results of this study indicate that $A$. hemistoma, unlike larger medusan species, occupies a broad trophic niche as a microplanktonic omnivore but that this function has not been appreciated, primarily as a result of the methods previously used to study medusan feeding.

\section{Methods}

In situ gut contents-The study was carried out during two research cruises in the southern Adriatic Sea $\left(42^{\circ} \mathrm{N}\right.$, $18^{\circ} \mathrm{E}$ ) during June 2002 and July 2003. Medusae were collected in shallow $(<25 \mathrm{~m}, 3-5 \mathrm{~min}$ in duration) vertical plankton tows (200- $\mu \mathrm{m}$ mesh) in the southern Adriatic Sea $\left(42^{\circ} \mathrm{N}, 18^{\circ} \mathrm{E}\right)$ in July 2003. Costello and Colin (2002) previously showed that plankton net feeding by ambush hydromedusae, such as A. hemistoma, did not influence gut content data because they rapidly retract their tentacles when disturbed. Prey-selection patterns were examined by comparing the gut contents of medusae captured simultaneously that were examined either directly, while alive, or after preservation with $5 \%$ formalin. Live individuals were sorted from the tow, placed onto a microscope slide, examined immediately using a stereomicroscope, and photographed. A cover slip was placed on top of the medusa and the gut was then examined and photographed using a compound micro- 


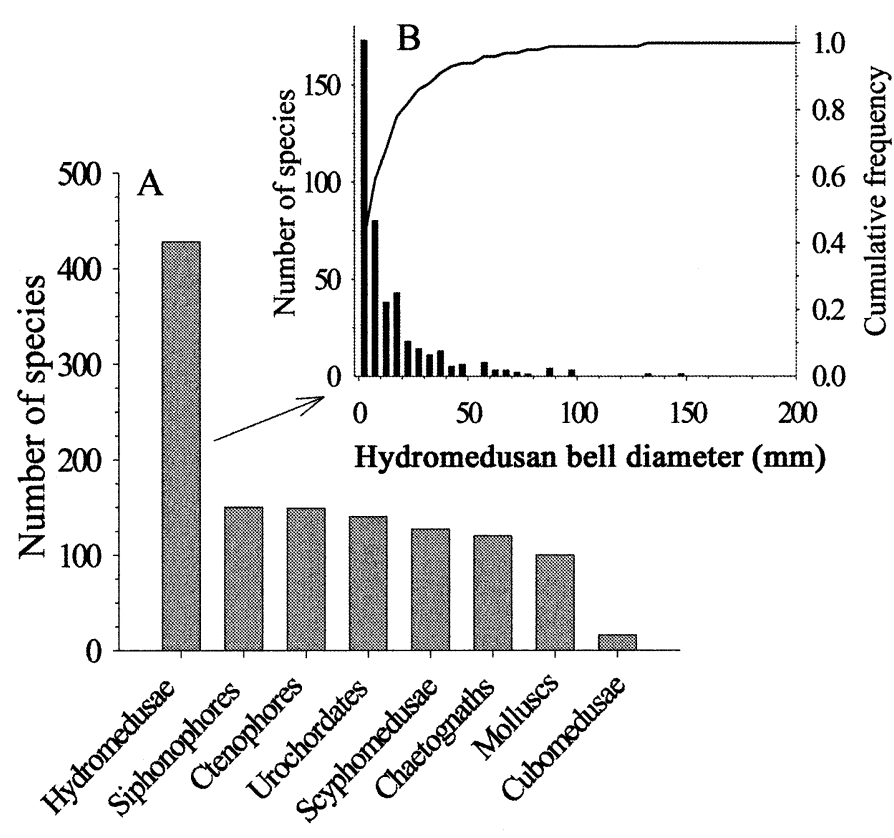

Taxa

Fig. 1. (A) Species diversity of major gelatinous zooplanktonic taxa and (B) size frequency distribution of hydromedusan species. The line in (B) represents the cumulative size frequency of species. The number of hydromedusan species in (A) is probably an underestimate because a more recent review (Bouillon and Boero 2000) estimates there are 842 valid species in the taxon. Data for (A) are based on Mayer (1910; scyphomedusae and cubomedusae), Kramp (1959), Wrobel and Mills (1998; pelagic mollusks), and Pechenik (2000; urochordates, chaetognaths, ctenophores). Data for (B) are based on Kramp (1959).

scope within 30 min of collection to identify gut fullness and prey composition. Placement of the cover slip compressed the guts, making them two dimensional, which enabled us to visually examine the contents without manually dissecting the guts. Medusae collected for preservation were sorted from the tow and immediately placed into small vials ( $2 \mathrm{ml}$ ) containing a 5\% formaldehyde solution and preserved for at least $48 \mathrm{~h}$ prior to examination. The gut contents of the preserved medusae were recorded as above. The contents of the vials were checked to ensure the contents of the medusan guts were not evacuated upon fixation.

Videography-Medusae were hand collected in jars by SCUBA divers and then placed into 200-ml clear-glass filming vessels with large enough dimensions to ensure medusa foraging was not influenced. Natural prey assemblages that were collected from surface plankton tows $(30-\mu \mathrm{m}$ mesh) were added to the vessels at natural relative proportions but concentrated to increase the number of predator-prey encounters observed. The medusae were videotaped while feeding using a side-lit microvideographic technique previously described by Costello and Colin (1994). Size scales were recorded by periodically placing a ruler in the filming vessel. Each individual medusa was observed for $0.5-2 \mathrm{~h}$.

Our initial observations identified a ciliary current that passed water through the extended tentacles of a feeding $A$.

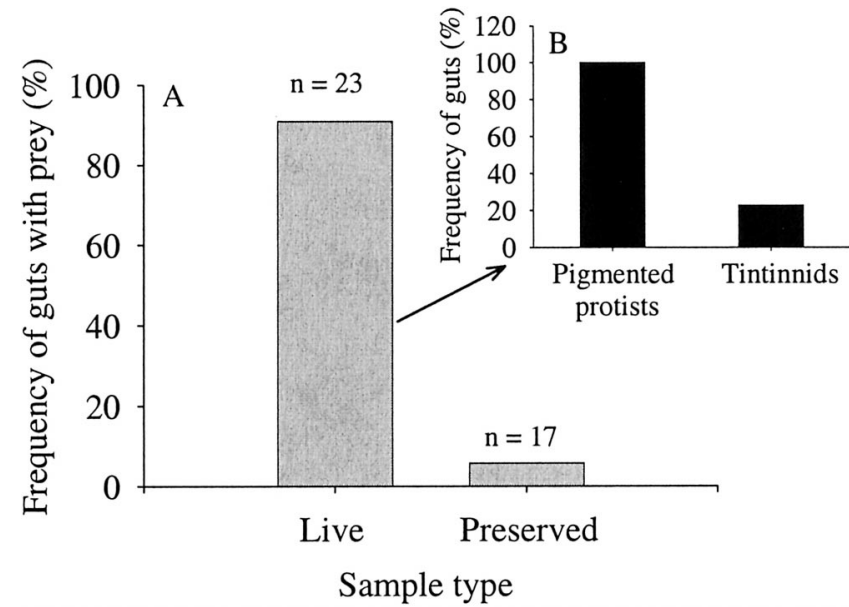

Fig. 2. Prey gut contents of the trachymedusa A. hemistoma. (A) Frequency of gut contents in live and preserved (5\% formaldehyde solution) A. hemistoma from the same date and site in the Adriatic Sea. (B) Frequency of guts of live A. hemistoma examined within $0.5 \mathrm{~h}$ of collection containing particular prey types.

hemistoma. To quantify the flow field around the medusae, natural particles were tracked for 5 frames and the distance and direction traveled were measured. Particle vectors were derived from the calculated particle speeds and the observed direction relative to the medusan bell. Mechanisms of prey capture were examined by observing and recording the outcome of each encounter event with prey (defined as a contact of the prey with the tentacle of the medusa) that occurred throughout the filming duration,

$$
\begin{array}{r}
\text { encounter } \underset{\text { medusa reaction }}{\longrightarrow} \underset{\text { prey capture }}{\longrightarrow} \text { prey ingestion } \\
\text { no reaction by medusa }
\end{array}
$$

A reaction was defined as a rapid contraction of the contacted tentacle toward the manubrium and a capture was identified when the medusa transferred the prey to the manubrium. We do not show ingestion results because all of the prey that the medusae reacted to and captured resulted in successful ingestion.

\section{Results}

The formalin-preserved medusae contained only one prey item-a single copepod nauplius. In contrast, the guts of live medusae (100\% of individuals) contained a variety of protistan remains (Fig. 2). Most of the protists in the guts of $A$. hemistoma were unidentifiable, and only individuals with hard structures, such as tintinnids or thecate dinoflagellates, could be identified. Most of the medusan guts were dominated by green-pigmented material. The disparity in gut contents between the two methods probably reflects the poor preservation of nonloricate protists in solutions such as formaldehyde (Gifford and Caron 2000). The scarcity of metazoan prey in the guts of preserved A. hemistoma is consistent with previous reports of in situ gut contents of other small hydromedusae, such as Rathkea octopunctata (Zelickman et al. 1969).

Video analysis revealed that $A$. hemistoma forages as an 


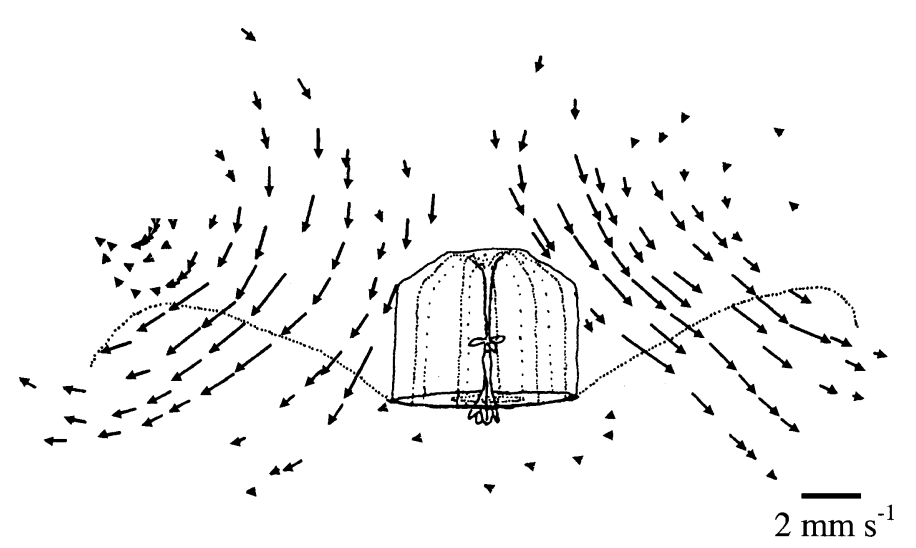

Fig. 3. Flowfields generated by ciliated tentacles of A. hemistoma (bell diameter $=3.5 \mathrm{~mm}$ ). Only two tentacles are shown; $A$. hemistoma typically has 16 tentacles.

ambush predator by sitting motionless with its tentacles extended out from the bell margin (Fig. 3). The tentacle position of the videoed medusae was the same as that observed by the divers in the field. The only movement observed was by the tips of the tentacles, which moved slowly in a circular motion. We also observed a flow of water through the tentacles created by cilia that line the tentacles (Fig. 3). The cilia entrained water from above the medusae down to and through the extended tentacles. The current velocity decreased moving away from the bell, with maximum velocities of around $2 \mathrm{~mm} \mathrm{~s}^{-1}$ occurring adjacent to the tentacles and decreasing to near $0.04 \mathrm{~mm} \mathrm{~s}^{-1}$ near the bell and the tips of the tentacles.

Flow through the tentacles was effective at entraining and drawing in nonmotile diatoms as well as acantharia and less motile protists (e.g., dinoflagellates and flagellates) to the capture surfaces. Therefore, the ciliary-driven current appeared to serve as a feeding current. However, nauplii and copepods were not entrained by the feeding currents. Instead, they encountered $A$. hemistoma by randomly jumping into the tentacles from regions outside the flow field (i.e., the side of the medusae). However, contact between prey and tentacles did not always result in prey capture. A. hemistoma did not react to nonmotile prey, and, thus, none of the encounters with acantharia, diatoms, or dead nauplii resulted in a capture (Table 1). A. hemistoma reacted to motile prey by rap- idly directing the contacted tentacle toward the manubrium. Tentacle contractions could transfer the captured prey to the manubrium within $0.03 \mathrm{~s}$ after contact. However, a reaction did not ensure a capture. Retention success (captures/reactions to encounters) varied significantly between less motile protists and highly motile copepods (Table 1, Tukey-Kramer post hoc test, $p<0.05$ ). While $\approx 80 \%$ of less motile protists were retained and captured after contact, only $\approx 33 \%$ of highly motile copepods were retained because most copepods escaped after contact. Therefore, although A. hemisto$m a$ was able to capture prey that ranged in size from 25 to $2,000 \mu \mathrm{m}$, actual prey ingestion patterns were affected by both A. hemistoma's feeding behavior (i.e., reaction to encounters) and the behavior of potential prey (i.e., escape reaction) (Table 1).

\section{Discussion}

Both the gut-content data and the prey-capture observations demonstrate that A. hemistoma is capable of feeding on prey ranging from green-pigmented protists to heterotrophic copepods. The high frequency of protistan prey in the diet suggests that A. hemistoma is well adapted as a grazer of protists. This is demonstrated by the use of a specific feeding adaptation-i.e., a feeding current-that is only effective at capturing protists and other small plankton. The possession of ciliary feeding currents is not unique to this species. The cellular organization and coordination of tentacular cilia involved in feeding current generation has been described for another widespread coastal-oceanic hydromedusa, Aglantha digitale (Mackie et al. 1989). No other small hydromedusae have been examined for similar traits.

A. hemistoma also utilizes ambush predation to encounter and capture larger, more motile metazoan prey. Ambush predation is the commonly observed feeding strategy for many hydromedusa and siphonophore species and relies on prey inadvertently swimming into outstretched tentacles. This appears to be the primary mechanism of encounter and prey capture of copepod nauplii and copepods. This combination of foraging strategies resulted in simultaneous ambush entanglement and feeding-current generation.

The resulting ingestion pattern included prey spanning three orders of magnitude in length. Perhaps more important than the overall size range, consumption of protists, partic-

Table 1. Summary of the prey encounter events of Aglaura hemistoma on different prey types. Reactivity (No. of reactions/No. of encounters) is the mean (SE) of the percent of the encounters to which the medusae react. Retention efficiency (No. of captures/No. of reactions) is the mean (SE) of the percent of the time that a reaction to prey resulted in a capture. Values indicated with an asterisk (*) are significantly different from each other (Tukey-Kramer, $p<0.05$ ).

\begin{tabular}{lcccccc}
\hline \hline \multicolumn{1}{c}{ Prey type } & $\begin{array}{c}\text { No. of } \\
\text { medusae } \\
(n)\end{array}$ & $\begin{array}{c}\text { Total } \\
\text { No. of } \\
\text { encounters }\end{array}$ & $\begin{array}{c}\text { Mean } \\
\text { encounters } \\
\text { per medusae }\end{array}$ & $\begin{array}{c}\text { Prey } \\
\text { motility }\end{array}$ & $\begin{array}{c}\text { Reactivity } \\
(\%)\end{array}$ & $\begin{array}{c}\text { Retention } \\
\text { efficiency } \\
(\%)\end{array}$ \\
\hline Diatoms & 4 & 15 & 3.8 & no & 0.0 & na \\
Acantharians & 3 & 16 & 5.0 & no & 0.0 & na \\
Dead nauplii & 3 & 7 & 2.3 & no & 0.0 & na \\
Unidentified protist & 7 & 29 & 4.1 & yes & $73.0(7.5)$ & $80.5(7.6)^{*}$ \\
Nauplii & 10 & 32 & 3.2 & yes & $59.2(14.0)$ & $67.4(11.1)$ \\
Copepods & 6 & 8 & 1.5 & yes & $100(0)$ & $33.3(16.7)^{*}$ \\
\hline
\end{tabular}


Table 2. Maximum seasonal abundance of dominant hydromedusan species found in different marine systems. The abundance per $\mathrm{m}^{3}$ and season are only for the species identified. Also listed is the total number of hydromedusan species identified in the studies.

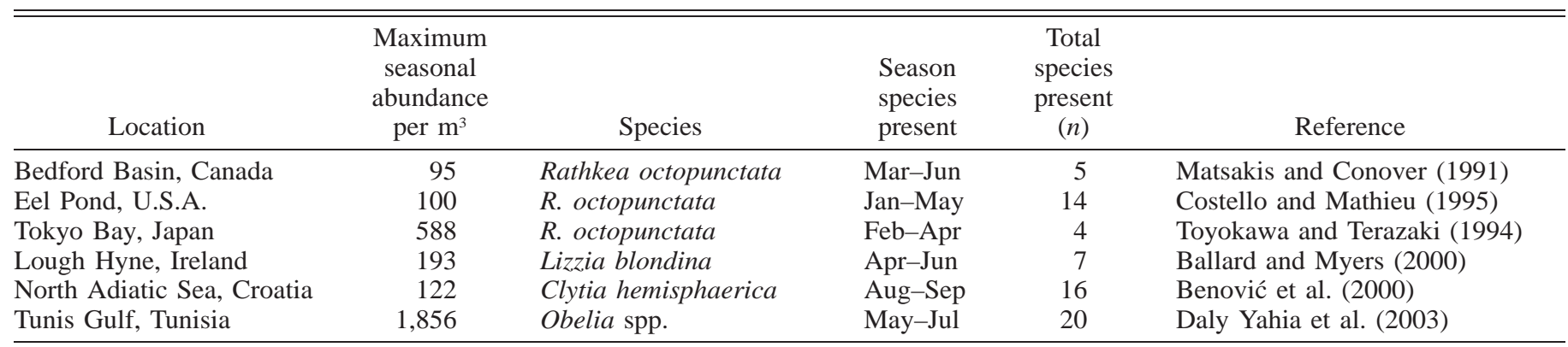

ularly chlorophyll-bearing (identified by green pigmentation) protists, extends the trophic range of A. hemistoma. Rather than supporting the conventional view of medusae as top predators of mesozooplankton, the ingestion patterns and feeding mechanisms possessed by A. hemistoma suggest that the medusa is omnivorous, similar to a variety of calanoid copepod species.

Although previously undocumented, it is perhaps not surprising to find that A. hemistoma, a small hydromedusa (bell diameter of $4 \mathrm{~mm}$ ), feeds on small protistan prey because the correlation between predator and prey size has long been established (Hansen et al. 1997). Because A. hemistoma is larger than approximately $40 \%$ of the adult hydromedusan species (Fig. 1), we predict that many members of this poorly studied group also feed as omnivores. In fact, the cumulative size distribution of hydromedusan species demonstrates that adults of most species $(>60 \%)$ are less than 1 $\mathrm{cm}$ and $>40 \%$ are less than $5 \mathrm{~mm}$ in diameter. The lack of documentation of omnivory among these small hydromedusae may be due to the problems associated with their small size and fragile body composition compared with other common planktonic taxa. Additionally, when examination has occurred, poor preservation of protistan prey in hydromedusan guts may have obscured this important trophic link (Fig. 2).

From an historical perspective, hydromedusan feeding on microplankton probably has a long evolutionary history. Hydromedusae evolved many millions of years before most other metazoan plankton, during a period when protists comprised the major food resource available to hydromedusae in the pelagic environment (Rigby and Milsom 2000). Continued use of this resource in contemporary oceans may represent a widespread and persistent trophic niche occupied by small hydromedusae throughout the evolution of marine plankton communities.

Are omnivorous hydromedusae capable of impacting primary production? In other words, are there enough hydromedusae present and do they feed with rates sufficient to counter phytoplankton growth rates? Unfortunately, ingestion rates on protistan prey are unknown. However, there are several studies that have measured hydromedusa abundances (Table 2). These studies indicate that, in coastal systems, hydromedusa populations are highly seasonal and they often coincide with seasonal phytoplankton blooms (Matsakis and Conover 1991; Toyokawa and Terazaki 1994; Costello and
Mathieu 1995). Seasonal peak abundances can reach densities similar to copepods and, with reasonable ingestion rates, could likely impact a portion of primary production. We suspect hydromedusae have less impact on primary production in oligotrophic systems, where the populations are not as seasonal and do no reach such high densities (Benović et al. 2000). However, small hydromedusae do not form sinking fecal pellets. Therefore, omnivorous hydromedusae in oligotrophic regimes may be remineralizers of nutrients, much as the microbial loop serves to prevent export of nutrient from these surface waters.

Our study indicates that the trophic roles of small hydromedusae in different systems are not understood and may be more important than previously thought. To understand their impact, more studies are needed that examine the prey selection, ingestion rates, and population biology of small hydromedusae. Although quantitative documentation of protistan feeding by small hydromedusae is a new challenge, the underlying process may well be as ancient as the first metazoan solutions to the planktonic environment.

\section{References}

Ballard, L., AND A. Myers. 2000. Observations on the seasonal occurrence and abundance of gelatinous zooplankton in Lough Hyne, Co. Cork, South-west Ireland. Proc. Royal Irish Acad. 100B: $75-83$.

BEHRENDS G., AND G. SchneIDER. 1995. Impact of Aurelia aurita medusae (Cnidaria, Scyphozoa) on the standing stock and community composition of mesozooplankton in the Kiel Bight (western Baltic Sea). Mar. Ecol. Prog. Ser. 127: 39-45.

Benović, A., D. Lučić, AND V. OnOFRI. 2000. Does change in an Adriatic hydromedusan fauna indicate an early phase of marine ecosystem destruction? Mar. Ecol. 21: 221-231.

Bouillon, J. 1999. Hydromedusae, p. 385-465. In D. Boltovskoy [ed.], South Atlantic zooplankton. Backhuys.

- AND F. BOERO. 2000. The hydrozoa: A new classification in the light of old knowledge. Thalassia Salentina 24: 1-296.

Costello, J. H., AND S. P. Colin. 1994. Morphology, fluid motion and predation by the scypohmedusa Aurelia aurita. Mar. Biol. 121: $327-334$.

, AND —. 2002. Prey resource utilization by coexistent hydromedusae from Friday Harbor, Washington. Limnol. Oceanogr. 47: 934-942.

— AND H. W. Mathieu. 1995. Seasonal abundance of medusae in Eel Pond, Massachusetts, USA during 1990-1991. J. Plankton Res. 17: 199-204. 
Daly Yahia, M. N., J. Goy, and O. Daly Yahia-Kefi. 2003. Distribution and ecology of medusae and scyphomedusae (Cnidaria) in Tunis Gulf (SW Mediterranean). Oceanologica Acta. 26: 645-655.

GIFFORD, D. J., AND D. A. CARON. 2000. Sampling, preservation, enumeration and biomass of marine protozooplankton, p. 201221. In R. Harris, P. Wiebe, J. Lenz, H. R. Skjoldal, and M. Huntley [eds.], ICES Zooplankton Methodology Manual. Academic.

Hansen, B., P. K. BJornsen, and P. J. Hansen. 1997. The size ratio between planktonic predators and their prey. Limnol. Oceanogr. 39: 395-403.

KramP, P. L. 1959. The hydromedusae of the Atlantic Ocean and adjacent waters. Dana-Rep. 46: 1-283.

Mackie, G. O., C. Nielsen, And C. L. Singla. 1989. The tentacle cilia of Aglantha digitale (Hydrozoa: Trachylina) and their control. Acta Zool. 70: 133-141.

Matsakis, S., And R. J. Conover. 1991. Abundance and feeding of medusae and their potential predators on other zooplankton in Bedford Basin (Nova Scotia, Canada) during spring. Can. J. Fish. Aquat. Sci. 48: 1419-1430.

MAYER, A. G. 1910. Medusae of the world. Carnegie Institute of Washington.
Pechenik, J. A. 2000. Biology of the invertebrates, 4th ed. McGraw Hill.

Purcell, J. E., AND C. E. Mills. 1988. The correlation between nematocyst types and diets in pelagic hydrozoa, p. 463-485. In D. A. Hessinger and H. M. Lenhoff [eds.], The biology of nematocysts. Academic.

Rigby, S., AND C. V. Milsom. 2000. Origins, evolution and diversification of zooplankton. Annu. Rev. Ecol. Syst. 31: 293-313.

ToyoKawA, M., AND M. TERAZAKI. 1994. Seasonal variation of medusae and ctenophores in the innermost part of Tokyo Bay. Bull. Plankton Soc. Japan. 41: 71-75.

Wrobel, D., AND C. E. MiLls. 1998. Pacific coast pelagic invertebrates: A guide to the common gelatinous animals. Monterrey Bay Aquarium.

Zelickman, E. A., V. I. Gelfand, And M. A. Shifrin. 1969 Growth, reproduction and nutrition of some Barents Sea hydromedusae in natural aggregations. Mar. Biol. 4: 167-173.

Received: 7 July 2004

Accepted: 2 January 2005 Amended: 15 February 2005 